\title{
Self-healing of Micro-cracks in Engineered Cementitious Composites
}

\author{
Suryanto, B. ${ }^{*}$, Wilson, S.A. ${ }^{1}$, and McCarter, W.J. ${ }^{1}$
}

\begin{abstract}
The performance of an Engineered Cementitious Composite (ECC) to self-heal micro-cracks under a controlled laboratory environment is presented. Ten dog-bone shaped samples were prepared; five of them were preloaded to known strains and then left to heal in water in a temperature-controlled laboratory. Ultrasonic pulse velocity (UPV) measurements were undertaken to monitor the crack-healing process. It was found that all samples exhibited recoveries in UPV and were able to recover to between $96.6 \%$ and $98 \%$ of their pre-test UPV values over a period of four weeks. An accelerated rate of healing was observed in the initial two-day period immediately following the preloading test.
\end{abstract}

Keywords: Cementitious composite, ECC, self-healing, crack, ultrasonic pulse velocity.

\section{Introduction}

There is worldwide concern relating to the ever increasing cost of repair and maintenance of concrete structures, primarily as a result of premature deterioration and cracking. In the United Kingdom (UK), for example, approximately half of the $£ 110 \mathrm{bn}$ construction output in 2010 was spent on maintenance and refurbishment [1], with a quite a large portion devoted to concrete structures. More recently, the Institution of Civil Engineers awarded UK infrastructure a ' $\mathrm{C}$ ' grade [2] and it was estimated that $£ 383 \mathrm{bn}$ in investment is required by 2020 to upgrade the current infrastructure to an acceptable standard [3]. The need for large investment is not exclusive to the UK and is of primary concern in many developed countries worldwide, including the US and Japan [4,5]. This issue is partly due to the brittle nature of concrete and partly caused by poor construction quality and practice during the construction boom after the Second World War. During the service life of these structures, cracking is therefore inevitable and when this occurs within the cover-zone of concrete structures, the deterioration processes are accelerated.

An illustration on how required maintenance over the lifetime of a reinforced concrete structure impacts on total cost is given in Figure 1. Line 1 represents the expected performance of a reinforced concrete structure built with regular concrete.

A structure is generally designed to deliver performance well above the required performance, in order to make sure that deterioration of the concrete and/ or reinforcing steel will not impair the serviceability and integrity of the structure (i.e. the performance level is above the threshold level).

${ }^{1}$ School of Energy, Geoscience, Infrastructure and Society; Institute for Infrastructure and Environment, Heriot-Watt University, Edinburgh, UNITED KINGDOM.

*Corresponding author's email: b.suryanto@hw.ac.uk

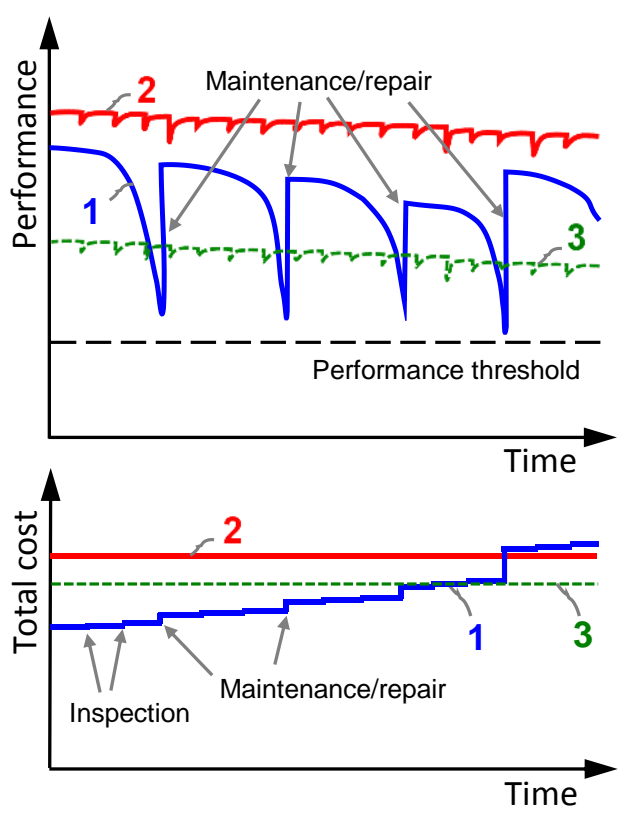

Figure 1. Schematic of the Potential Cost Benefits of Selfhealing Materials (adapted from [6])

Due to deterioration, however, the structure needs to be repaired and maintained on a regular basis to bring the overall performance back to an acceptable level. The expenditure associated with this maintenance will add to the initial construction cost and therefore increase the total cost. Line 2 shows the performance of a material which is able to heal cracks by itself. The lifetime of the structure prior to any 'major' repair is likely to be extended when compared to a similar structure built with regular concrete thereby reducing maintenance costs. While the initial cost of construction using this advanced material is greater, this would be offset by far lower required maintenance expenditure and hence such a material would likely offer economic advantages in the long term. The enhanced performance of the material could allow further optimization to be done, leading to a further cost reduction (Line 3). 
This paper presents an investigation into the selfhealing performance of an advanced cement-based material termed an Engineered Cementitious Composite (ECC). An ECC is known for its high tensile strain capacity, typically well excess $1 \%$, and a controllable crack width, typically less than $0.1 \mathrm{~mm}$ under service load [7]. It is these unique properties of ECC that enable micro-cracks in ECC to heal without human intervention. Studies have shown that the self-healing performance of ECC is robust [8-13], with healing being found more effective in crack widths of less than 50 $\mu \mathrm{m}$. These studies have also shown that self-healing in ECC offers recovery of mechanical properties such as strength and stiffness. The authors have recently developed an ECC mixture $[14,15]$ and it is the interest of this paper to assess the self-healing performance of this mixture under a controlled laboratory environment. It is well known that small crack width is a key factor in encouraging self-healing in cement-based systems [16,17]; therefore, this study will be useful not only to confirm self-healing capability of the mixture, but also to confirm whether or not the developed mixture can exhibit controlled crack width. A parallel study was undertaken to assess the performance of the mixture in the natural environment and the results are presented in reference [15].

\section{Experimental Program}

The experimental program undertaken involved two series of tests (see Table 1). In the first series, three samples with dimensions of $50 \times 50 \times 250 \mathrm{~mm}$ (long) were prepared (Figure 2 ). These prism samples were simply cured in water for 28 days to investigate the influence of cement hydration. In the second series, ten dog-bone samples with dimensions to JSCE recommendations [18] (Figure 2) were produced to allow direct assessment of the self-healing performance of ECC in a controlled laboratory environment. Of these ten samples, samples 1-3 were deliberately loaded to failure to obtain the tensile strain capacity; samples 4 and 5 were cured in water and served as control samples; samples 6 and 7 were precracked to $30 \%$ to the tensile strain capacity; and samples 8-10 to $60 \%$ of this value. In addition, three $50 \mathrm{~mm}$ cubes were prepared to assess the compressive strength.

Table 1. Summary of Experimental Programme

\begin{tabular}{ccl}
\hline Shape & Sample No & \multicolumn{1}{c}{ Remarks } \\
\hline Prism & P1-P3 & $\begin{array}{l}\text { Used to monitor the influence } \\
\text { of hydration } \\
\text { Tested to failure to obtain } \\
\text { stress-strain curves }\end{array}$ \\
& $1-3$ & $\begin{array}{l}\text { Control samples } \\
\text { Precracked at 30\% tensile } \\
\text { strain capacity } \\
\text { Precracked at 60\% tensile } \\
\text { strain capacity }\end{array}$ \\
\hline
\end{tabular}
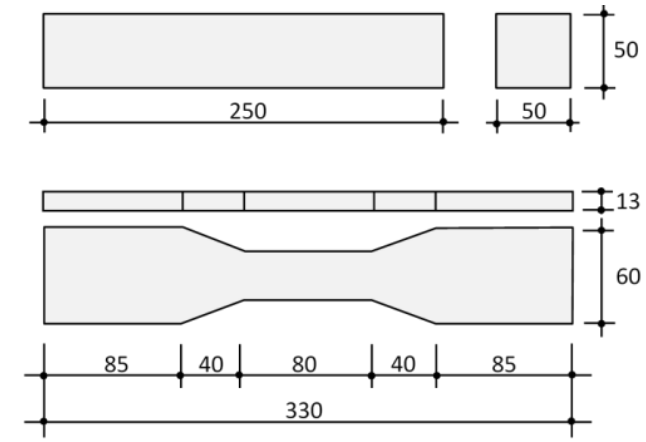

Figure 2. Dimensions of Dog-bone and Prism Test Samples

\section{Materials}

The binder comprised CEM I $52.5 \mathrm{~N}$ cement to BS EN197-1:2011 [19] and a fine fly-ash (Superpozz SV80, ScotAsh). The fly-ash-to-cement (FA/C) ratio was set constant at 1.8 , while the water/binder $(\mathrm{w} / \mathrm{b})$ ratio was 0.28 (see Table 2). A fine silica sand (RH110, Minerals Marketing) with an average particle size of $120 \mu \mathrm{m}$ was used at a constant sandto-cement ratio of 0.6 by mass. Their oxide analyses are presented in Table 3. A polycarboxylate highrange water-reducing admixture (Glenium C315, BASF) was added at a fixed dosage rate of $1 \%$ by mass of cement. Polyvinyl alcohol (PVA) fibers (RECS15, Kuraray) were used at a fixed dosage of $2 \%$ by volume. The PVA fibers had an average length of $12 \mathrm{~m}$, a diameter of $39 \mu \mathrm{m}$ and a tensile strength of $1600 \mathrm{MPa}$.

Table 2. Materials Mix Proportions

\begin{tabular}{|c|c|c|c|c|c|c|}
\hline $\begin{array}{l}\text { CEM I } \\
\left(\mathrm{kg} / \mathrm{m}^{3}\right) \\
\end{array}$ & $\begin{array}{c}\text { FA } \\
\left(\mathrm{kg} / \mathrm{m}^{3}\right)\end{array}$ & $\begin{array}{c}\text { Silica } \\
\text { sand } \\
\left(\mathrm{kg} / \mathrm{m}^{3}\right)\end{array}$ & $\mathrm{w} / \mathrm{b}^{*}$ & $\begin{array}{l}\text { HRWR } \\
\left(\mathrm{kg} / \mathrm{m}^{3}\right)\end{array}$ & $\begin{array}{l}\text { PVA }^{\&} \\
\left(\mathrm{~kg} / \mathrm{m}^{3}\right)\end{array}$ & $\begin{array}{c}F_{28} \\
(\mathrm{MPa})\end{array}$ \\
\hline 454 & 818 & 273 & 0.28 & 4.54 & 26 & $33^{\#}$ \\
\hline
\end{tabular}

\section{Sample preparation and curing}

The mixing process was performed using a 10-litre planetary motion mixer. A strict mixing regime was incorporated to ensure that all ingredients, particularly the PVA fibers, thoroughly distributed throughhout the ECC mix. This process began with mixing all dry components excluding the fibers along with $80 \%$ of the water at 'low' speed. After one minute, the superplasticizer was introduced and after a further two minutes, the remaining $20 \%$ of the water was added and the mixer speed was increased to 'high'. One and a half minutes later, the PVA fibers were added and the mixer was again switched to the low' speed and allowed to mix for one minute. The mixer speed was increased to 'high' again and the components were mixed for another four minutes to ensure that the fibers were thoroughly mixed. The mixer was finally switched to 'low' speed and mixing continued for 30 seconds. 
Table 3. Oxide Analysis and Physical Properties of Fly-ash and Silica Sand (wt\%)

\begin{tabular}{|c|c|c|}
\hline & Fly-ash & $\begin{array}{l}\text { Silica } \\
\text { sand }\end{array}$ \\
\hline \multicolumn{3}{|l|}{ Chemical analysis } \\
\hline $\mathrm{SiO}_{2}$ & 52.7 & 98.8 \\
\hline $\mathrm{Al}_{2} \mathrm{O}_{3}$ & 26.6 & 0.21 \\
\hline $\mathrm{Fe}_{2} \mathrm{O}_{3}$ & 5.6 & 0.09 \\
\hline $\mathrm{K}_{2} \mathrm{O}$ & - & 0.03 \\
\hline $\mathrm{CaO}$ & 2.4 & - \\
\hline $\mathrm{MgO}$ & 1.2 & - \\
\hline $\mathrm{Na}_{2} \mathrm{O}$ equivalent & 1.7 & - \\
\hline $\mathrm{SO}_{4}$ & 0.3 & - \\
\hline Free $\mathrm{CaO}$ & 0.03 & - \\
\hline Total phosphate & 0.5 & - \\
\hline Loss on Ignition (LOI) & $<2.0$ & 0.14 \\
\hline \multicolumn{3}{|l|}{ Physical properties } \\
\hline Specific gravity & 2.20 & 2.65 \\
\hline Surface area $\left(\mathrm{m}^{2} / \mathrm{kg}\right)$ & 1300 & - \\
\hline Fineness (\% retained on $25 \mu \mathrm{m}$ ) & $<25$ & - \\
\hline \multicolumn{3}{|c|}{ Size distribution $(\mu \mathrm{m})$ and cumulative retained $(\%)$} \\
\hline 500 & - & 0.1 \\
\hline 355 & - & 0.5 \\
\hline 250 & - & 1.5 \\
\hline 180 & - & 6.0 \\
\hline 125 & - & 46.0 \\
\hline 90 & - & 83.0 \\
\hline 63 & - & 96.5 \\
\hline
\end{tabular}

Upon completion of the mixing process, the ECC was scooped and then poured into ten equally sized Plexiglas molds (see Figure 3). Extra care was taken when pouring the mixture to ensure even fiber distribution, particularly at the center narrower section of the molds of which the testing would be focused. Once the samples were cast, they were covered with polythene sheeting for 24 hours before being removed from the molds and then placed in a small curing tank for 13 days. The temperature at which the curing took place was controlled to $20 \pm 1^{\circ} \mathrm{C}$.

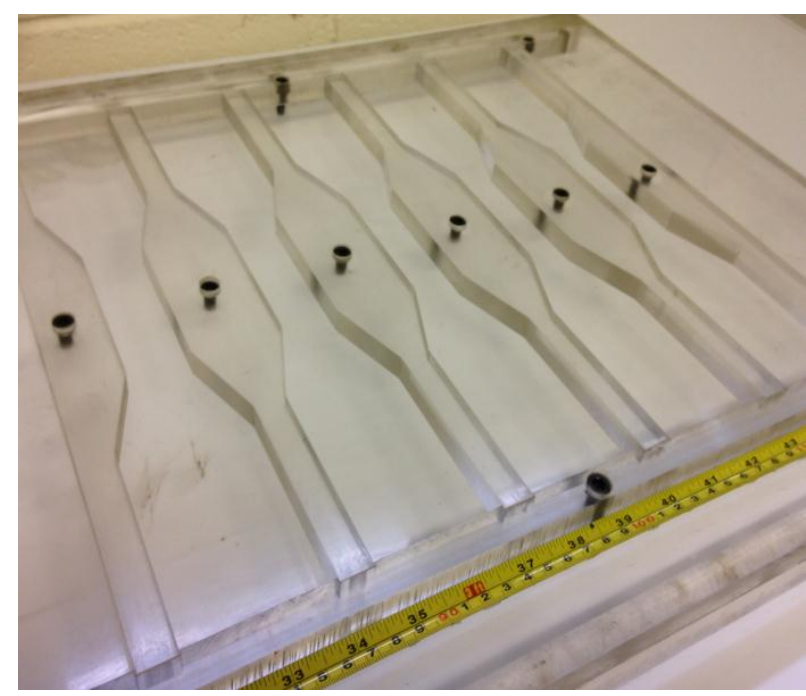

Figure 3. Plexiglass Mold used to Produce the Dog-bone Samples

\section{Testing and instrumentation}

A $100 \mathrm{kN}$ Instron 4206 machine was used to carry out the tensile tests. Each sample was gripped at either end by pneumatic grips and care was taken to ensure that the sample was aligned so as to minimize the eccentricity of the imposed tensile forces. To measure the axial deformation at the central section, two LVDTs were mounted at either side (see Figure 4(a)) and tensile strains were then determined from the displacement changes monitored from these two LVDT readings. Tensile stress was calculated from the imposed tensile loading divided by the cross sectional area of the slender section. Bluehill-2 computer software was used to control the testing apparatus and to enable continuous monitoring of the applied load and displacement. In addition, a 16-bit data acquisition device was used to record the output signals from the two LVDTs at a rate of $1 \mathrm{~Hz}$. Figure 4(b) displays the tensile stressstrain responses obtained from samples $1-3$. The average tensile strain capacity was found to be $2.7 \%$. Accordingly, tensile strains of $0.8 \%$ and $1.6 \%$ were determined as target initial strain values for samples preloaded to $30 \%$ and $60 \%$ of the ultimate tensile strain, respectively. These samples were then placed in the same curing tank as before and left to heal.

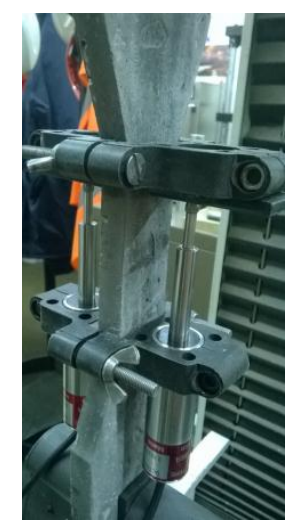

(a)

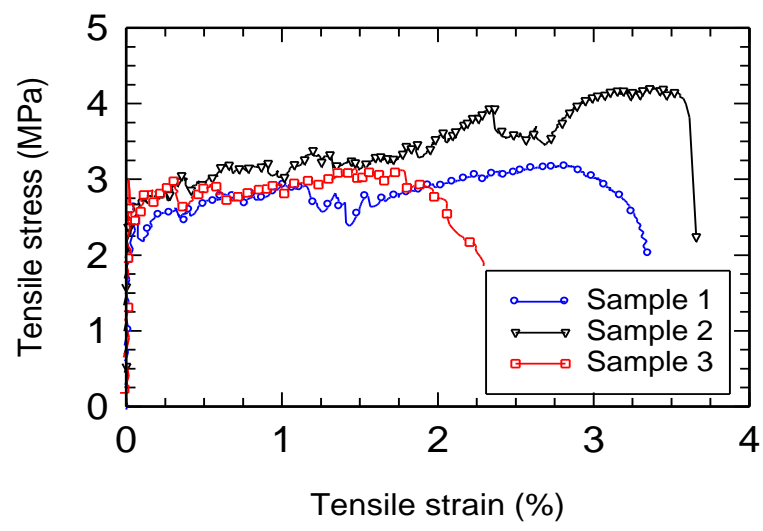

(b)

Figure 4. (a) Dog-bone Sample during Uniaxial Tensile Testing and (b) Tensile Stress-strain Responses of Samples 1-3 
To monitor the self-healing process in the ECC samples, ultrasonic pulse velocity (UPV) measurements were undertaken immediately prior to preloading, immediately after preloading, and over four weeks during the self-healing process. A PUNDIT apparatus was used, together with two $54 \mathrm{kHz}$ transducers. This apparatus was calibrated prior to taking any UPV measurements using a 26.0ps reference bar. Intimate contact with the specimen surface was achieved using a viscous gel. Measurements were undertaken by coupling the transducers with opposite ends of each sample (see Figure 5) and then by recording the indicated signal transit time.

\section{Data Analysis}

The UPV was calculated using Equation 1:

$$
v=\frac{L}{t}
$$

where $v$ is the UPV $(\mathrm{m} / \mathrm{s}), L$ is the distance between the transducers $(0.33 \mathrm{~m})$ and $t$ is the measured pulse transit time in (s). The ratio of the UPV recorded in a control sample before and after being submerged in water $\left(R_{c}\right)$ was computed using Equation 2 :

$$
R_{c}=\frac{v_{c, w}}{v_{c}}
$$

in which $v_{c, w}$ is the UPV of control samples during the self-healing test and $v_{c}$ is the UPV of the control samples before the test. This parameter gives an indication of continued hydration. A similar relationship (Equation 3) can be used for preloaded samples:

$$
R_{p}=\frac{v_{p, w}}{v_{p}}
$$

where $v_{p, w}$ is the UPV of the preloaded samples during the self-healing test and $v_{p}$ is the UPV of the same samples prior to preloading. This parameter provides an indication of the combined influence of micro-cracks, continued hydration and crack-healing. The normalized ratio $R_{n}$ can then be used to get an indication of the extent of (Equation 4) crackhealing:

$$
R_{n}=\frac{R_{p}}{R_{c}}
$$

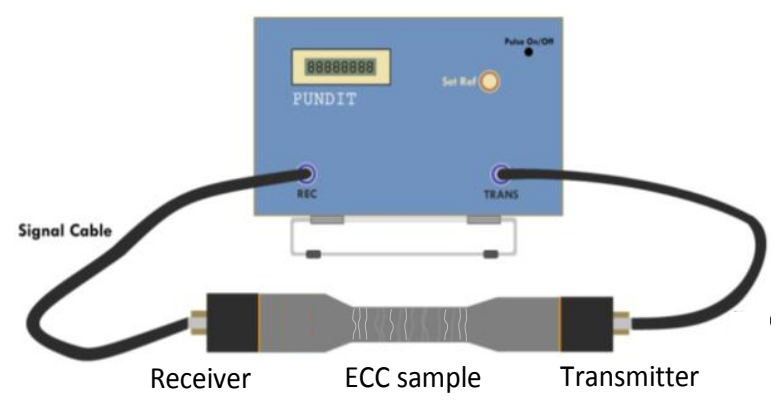

Figure 5. A Schematic Diagram of the UPV Tests

\section{Results and Discussion}

\section{Prism Samples}

Figure 6(a) presents the change in UPV with time over a period of 28 days after casting. It is apparent that there is a significant increase in UPV over the initial three days of hydration. At 1-day hydration, for example, the UPV attains an average value of $2828 \mathrm{~m} / \mathrm{s}$ with a COV of $0.5 \%$ and at 3-days hydration, this value has been increased to $3342 \mathrm{~m} / \mathrm{s}$ with a COV of $0.1 \%$. This rapid increase in UPV reflects intense microstructural changes as a result of cement hydration. After this, the hydration process has less effect on bulk UPV and the UPV appears to plateau. A slight increase in UPV can still be seen, with values of $3449 \mathrm{~m} / \mathrm{s}$ attained at 7 days, $3478 \mathrm{~m} / \mathrm{s}$ at 14 days and $3497 \mathrm{~m} / \mathrm{s}$ at 28 days. This slight increase in UPV can be attributed to pore-structure refinement resulting from on-going hydration and pozzolanic activity.

It has been generally established that UPV can be related to the physical properties of material such as the dynamic elastic modulus and density. If the ECC can be regarded as a homogeneous isotropic material, the dynamic elastic modulus of the material can be calculated using Equation 5 [20].
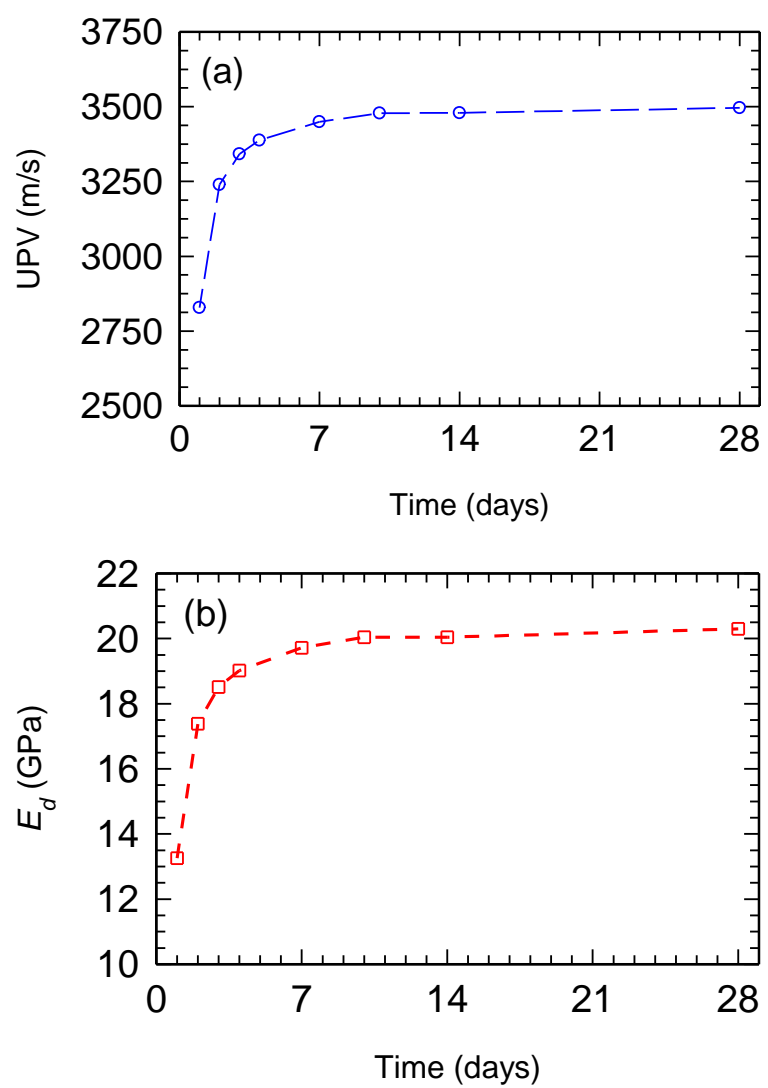

Figure 6. The Influence of Curing Time on (a) Bulk UPV and (b) Dynamic Modulus of Elasticity of Samples P1-P3 
$E_{d}=\frac{\left(1+v_{d}\right)\left(1-2 v_{d}\right)}{\left(1-v_{d}\right)} \rho v^{2}$

where $E_{d}$ is the dynamic modulus of elasticity, $v_{d}$ is the dynamic Poisson's ratio and $\rho$ is the mass density. Assuming a constant mass density of 1921 $\mathrm{kg} / \mathrm{m}^{3}$, which was measured at 28 days after casting, and a constant dynamic Poisson's ratio of 0.23 [16], the dynamic modulus of elasticity, $E_{d}$, can be computed using Equation 5 and the results are presented in Figure 6(b). It is apparent that increasing hydration time has a notable influence on the dynamic modulus of elasticity. Over the initial three days of curing, the dynamic elastic modulus increases rapidly from an average value of $13.3 \mathrm{GPa}$ at 1-day hydration to $18.5 \mathrm{GPa}$ at 3-days hydration. This value plateaus at approximately $20 \mathrm{GPa}$ at 10 days.

\section{Dog-bone Samples}

The normalized UPV taken from three control samples, $R_{c}$, is presented in Figure 7. As has been observed in the prism samples, a very slight increasing trend with exposure time can be observed $(<1 \%)$, which can be related to continual refinement of porestructure. To obtain the extent of initial damage and self-healing, the UPV values for the preloaded samples were normalized, in accordance with Equation 3 , and the results are presented in Figure 8. In general terms, the response can be divided into three distinct regions comprising: (i) a valley region at the left-hand side of the curve; (ii) a transition region of rapidly increasing normalized UPV values, resembling the early hydration response; and, (iii) a plateau on the right-hand side which extends over the remaining duration of the test.

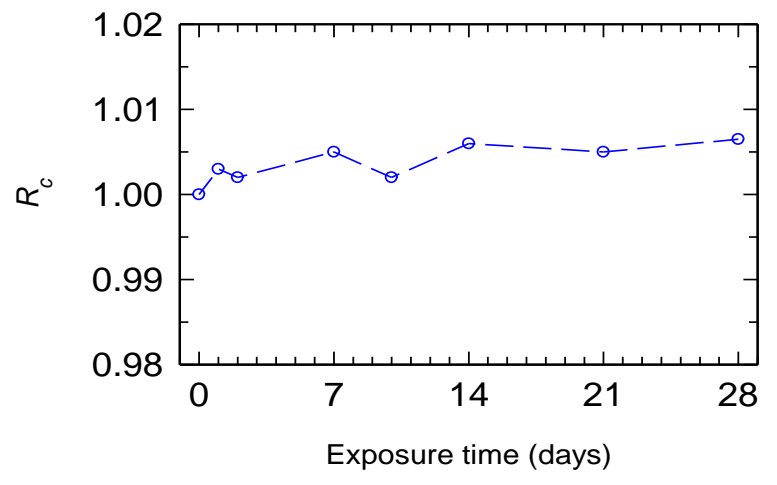

Figure 7. Normalized UPV Values for Samples 4 and 5

The depth of the valley can be associated with the extent of damage following a loading event. It is evident from Figure 8 that the normalized UPV decreases as the test samples are subjected to a greater initial strain, resulting in a downward displacement of the valley. As can be seen, the normalized UPV values drop to approximately $86 \%$ and $75 \%$ of their normalized pre-test values as the samples are damaged to $30 \%$ and $60 \%$ of the strain capacity, respectively. The larger drop in the normalized UPV values in samples tested to $60 \%$ of the tensile strain capacity is attributed to the presence of a larger number of micro-cracks which was also observed visually.

The rapid increase in UPV over the initial few days of exposure (see Figure 8), which resembles the early hydration shown previously (Figure 6(a)), reflects an intense self-healing activity. This pronounced healing activity may occur as a result of the hydration of either unhydrated or partially hydrated cement particles which were previously encapsulated by hydration products and thus unreachable by moisture. It is postulated that cracking can create channels through which moisture can then access these unhydrated/partially hydrated cement particles, allowing the hydration process to take place, thereby allowing these particles to grow and eventually seal the micro-cracks. Visual inspection of the sample surface after 14 days immersion in water show the presence of white striations (see Figure 9), indicating that the micro-cracks have been effectively healed. A more detailed analysis of the morphology and compositions of these healing products is currently being carried out.

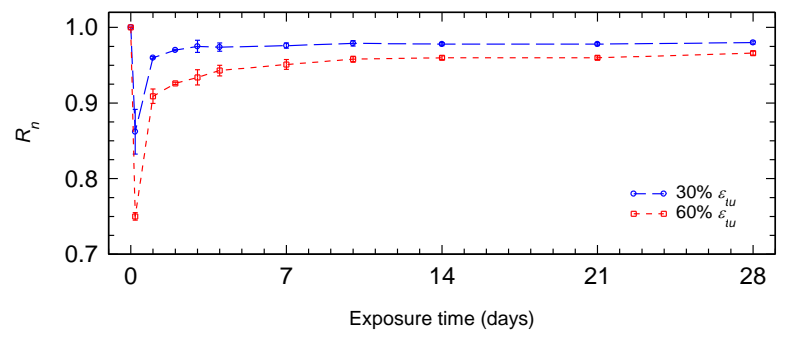

Figure 8. Normalized UPV for samples precracked at 30\% and $60 \%$ ultimate tensile strain ( $\varepsilon t u$ ). The error bars on the data points represent \pm 1 standard deviation from the mean value and where the error bar appears to be missing, the marker is larger than the error bar

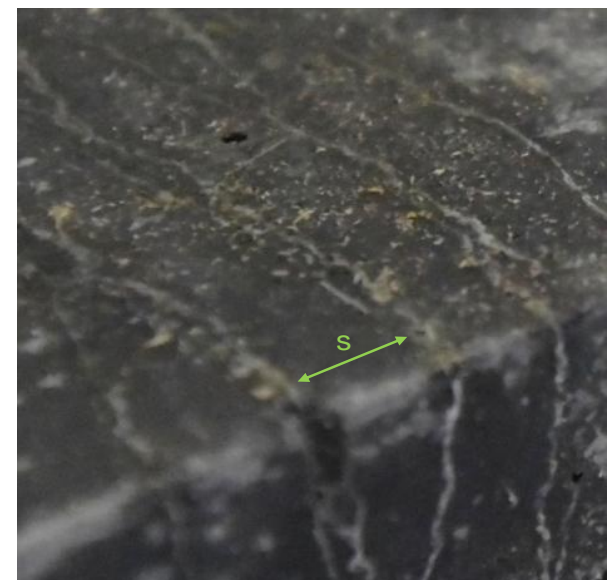

Figure 9. White striations observed on the surface of sample 10 after being immersed in water for 14 days. The average distance between the striations (average crack spacing), $\mathrm{s}$, is $\pm 3 \mathrm{~mm}$. 
It is also apparent from Figure 8 that the initial selfhealing rate is largely dictated by the extent of initial damage. In samples damaged to $30 \%$ and $60 \%$ of the tensile strain capacity, for example, average recoveries of $9.8 \%$ and $15.9 \%$ can be observed and this difference can be associated with the difference in the number of micro-cracks. This can be explained by the fact that in samples experiencing a greater initial tensile strain, a larger number of micro-cracks develop which then provides a larger surface area, in the form of crack surfaces. As the crack width remains small, healing products can therefore precipitate simultaneously on these crack surfaces, thereby leading to an apparent accelerated healing. This finding confirms the ability of the developed mixture to exhibit controlled crack width. Should the microcracks have widened significantly, the rate of healing would decrease, resulting in a much slower recovery in UPV [15].

From the results presented in Figure 8, it is also apparent that the normalized UPV in samples preloaded to $30 \%$ tensile strain capacity plateaus after three days immersion in water whereas in the other series of samples, this occurs after 10 days. The normalized UPV attain the values of $98 \%$ and $96.6 \%$ of the pre-test values for samples tested to $30 \%$ and $60 \%$ strain capacity, respectively. Further investigation is required to confirm the recovery in strength and stiffness.

\section{Conclusions}

The following conclusions can be drawn from the work presented:

1. The newly developed ECC mixture incorporating materials locally available in the UK exhibited the desired tensile strain hardening behavior and formation of micro-cracks of controlled width under tensile loading. It has been demonstrated that the material is proven capable of self-healing micro-cracks under a controlled laboratory environment.

2. From the test investigating the effect of continued hydration on bulk UPV, it was found that the PUNDIT apparatus was sensitive enough to monitor the early hydration of ECC. At 1-day hydration, the UPV attains an average value of $2828 \mathrm{~m} / \mathrm{s}$ and further increases to $3342 \mathrm{~m} / \mathrm{s}$ at 3 days hydration. The UPV plateaus after approximately 10 days of curing at a value of approximately $3500 \mathrm{~m} / \mathrm{s}$.

3. It was found that samples damaged to $30 \%$ and $60 \%$ of the tensile strain capacity were able to recover to between $96.6 \%$ and $98 \%$ of their pretest UPV values over a period of four weeks.

4. All samples showed significant recovery in the two-day period after the tensile test, with recovery being particularly profound in samples damaged to a greater extent. The faster recovery in samples damaged to a greater extent reflects simultaneous healing of a greater number of micro-cracks, indicating that the crack widths in these samples are comparable to those in samples damaged to a lesser extent. This finding supports the notion that the developed mixture exhibits controlled crack width. However, it was found that the more damaged samples did not exhibit the same total recovery extent of those damaged to a lesser extent.

\section{Acknowledgements}

The authors wish to acknowledge the support of Kuraray Japan and Kuraray Europe $\mathrm{GmbH}$ for providing the PVA fibers and BASF UK for donating the admixture. Financial support from the School of Energy, Geoscience, Infrastructure and Society, Heriot-Watt University, is gratefully acknowledged. Thanks also expressed to Ms. L. L. Teodoro for assistance in the experimental work as part of the Science without Borders Programme.

\section{References}

1. Cabinet Office, Government Construction Strategy, UK Government, London, 2011.

2. Institution of Civil Engineers. The State of the Nation: Infrastructure 2014, London, 2014.

3. UK HM Treasury, National Infrastructure Plan 2014, UK Government, London, 2014.

4. American Society of Civil Engineers, 2013 Report Card for America's Infrastructure, 2013.

5. Ozawa, K., Stock Management of CE Infrastructure in Asia, In: Fujino, Y. and Noguchi, N., Editors, Stock Management for Sustainable Urban Regeneration, Springer, Tokyo, 1-14, 2009.

6. van Breugel, K., Is There a Market for Selfhealing Cement-based Materials? Proceedings of the First International Conference on Self-Healing Materials, Delft, Netherlands, 18-20 April 2007, pp. 1-9.

7. Li, V.C., On Engineered Cementitious Composites (ECC): A Review of the Material and its Applications, Journal of Advanced Concrete Technology, 1(3), 2003, pp. 215-230.

8. Li V.C. and Yang E.H., Self-healing in Concrete Materials. In: van der Zwaag, S., Editor, Self Healing Materials: An Alternative Approach to 20 Centuries of Materials Science, Springer, Dordrecht, Netherlands, 161-193, 2007.

9. Yang Y., Lepech M.D., Yang E.H., and Li V.C., Autogenous Healing of Engineered Cementitious Composites under Wet-Dry Cycles, Cement and Concrete Research, 39(5), 2009, pp. 382-390. 
10. Qian, S., Zhou, J., and de Rooij, M.R., Selfhealing Behavior of Strain Hardening Cementitious Composites incorporating Local Waste Materials, Cement and Concrete Research, 31(9), 2009, pp. 613-621.

11. Kan, L.L., Shi, H.S., Sakulich, A.R., and Li, V.C., Self-healing Characterization of Engineered Cementitious Composites (ECC), ACI Materials Journal, 107(6), 2010, pp. 617-624.

12. Qian, S., Zhou, J., and Schlangen, E., Influence of Curing Condition and Precracking Time on the Self-healing Behavior of Engineered Cementitious Composites, Cement and Concrete Research, 32(9), 2010, pp. 686-693.

13. Yang, Y., Yang, E.H., and Li, V.C., Autogenous Healing of Engineered Cementitious Composites at Early Age, Cement and Concrete Research, 41(2), 2011, pp. 176-183.

14. Pourfalah, S. and Suryanto, B., Development of Engineered Cementitious Composite Mixtures using Locally Available Materials in the UK. Proceedings of the Infrastructure and Environment Scotland First Postgraduate Conference, Edinburgh, UK, 2013, pp. 75-78.
15. Suryanto, B., Wilson, S.A., McCarter, W.J., and Chrisp, T.M., Self-healing Performance of Engineered Cementitious Composites under Natural Environmental Exposure, Advances in Cement Research, 2015. DOI: 10.1680/adcr.15. 00022.

16. Edvardsen, C., Water Permeability and Autogeneous Healing of Cracks in Concrete, ACI Materials Journal, 96(4), 1999, pp. 448-454.

17. Reinhardt, H.W. and Jooss, M., Permeability and Self-healing of Cracked Concrete as a Function of Temperature and Crack Width, Cement and Concrete Research, 33(7), 2002, pp. 981-985.

18. Japan Society of Civil Engineers, Recommendations for Design and Construction of High Performance Fiber Reinforced Cement Composites with Multiple Fine Cracks (HPFRCC), Concrete Engineering Series 82, Testing Method 6-10. JSCE, Tokyo, Japan, 2008.

19. BS EN 197-1:2011, Cement: Composition, Specifications and Conformity Criteria for Common Cements, London: British Standards Institution, 2000.

20. Krautkrämer, J. and Krautkrämer, H. Ultrasonic Testing of Materials, Third edition, Springer Berlin Heidelberg, 1983. 